\title{
Cultivando Respeto (Cultivating Respect): Engaging the Latino Community
}

\author{
Arcela Nuñez-Alvarez, Marisol Clark-Ibáñez, Ana M. Ardón, Amy L. Ramos, and Michelle \\ Ramos Pellicia
}

\begin{abstract}
This article addresses an innovative approach to connecting an urban university with the surrounding neighborhoods comprised of Latino immigrants, who represent potential new students or current students' family members. The National Latino Research Center (NLRC) uses popular education, culturally informed, and linguistically relevant strategies to engage diverse Latino communities in the northern region of San Diego County in California. Methods of engaging the Latino community include cultivating long-term relationships, responding to time-sensitive community crises, facilitating inter-generational connections, presenting material in a culturally informed and relevant way, providing hands-on experiences with civic engagement, and growing partnerships within the university and among non-profits. Preliminary findings described a two-year study on civic engagement testing the effectiveness of a Spanishlanguage curriculum based on popular education offered (free) to members of urban and rural low-resourced Latino communities. The Center statistically correlated Latino community members' experiential learning, participating in social media, and voting with gains in civic engagement knowledge.
\end{abstract}

Keywords: Civic engagement; immigrants; university; popular education; human rights

\section{Introduction}

Many urban universities have existing Latino or emerging Latino communities. They represent current or future students. Finding meaningful ways to connect with the Latino community becomes a vital goal to the growth and relevance of the university. How do universities engage the local Latino community in meaningful and sustained ways? This article shares findings from a community program that was based on respectful, strength-based and human rights framework. This article also shares preliminary research findings that illuminate the efficacy of the approach.

The National Latino Research Center (NLRC) is an academic center chartered at California State University San Marcos (CSUSM). CSUSM has distinguished itself as a forward-focused institution, dedicated to preparing future leaders, building great communities and solving critical issues. With nearly 14,000 enrolled students, it is the only public four-year comprehensive university serving North San Diego and Southwest Riverside counties. The University is committed to creating a diverse and inclusive environment. The NLRC began in 1998 with the mission of promoting scientific and applied research, training, and the exchange of information that contribute to the knowledge and understanding of the rapidly growing U.S. Latino populations. The NLRC has long-term advocacy and educational experience with the Latino community in San Diego County, specifically youth and issues surrounding culture, education, health, and civic leadership. 
CSUSM serves the region known as North San Diego County, which encompasses cities along the CA-78 state highway. The CA-78 Corridor stretches from the coastal city of Oceanside into the inland city of Escondido and crosses the cities of Vista and San Marcos. The region's population of 653,852 is comprised of almost $40 \%$ Latinos, of which $90.9 \%$ are of Mexican origin (U.S. Census Bureau, 2011-2015 American Community Survey 5-Year Estimate).

\section{Statement of Need}

Civic engagement among Latinos and Latinas lags far behind White, Asian, and African American counterparts across every form of participation in California and nationally (Garcia Bedolla, 2012; Abrajano \& Alvarez, 2010). Latinos in San Diego are disengaged from civic life and have the lowest voter count and rate of voter turnout (Equality Alliance of San Diego County, 2011). Simply put, Latinos are the most "civically alienated" group and the "least likely to be broadly engaged” (Sullivan \& Godsay, 2014).

Although researchers have well documented individual experiences that motivate civic engagement, possible links between Latinos' cultural backgrounds (e.g., familial connections, geographic locations) and civic engagement are not commonly empirically studied. We theorize that civic and political participation is a continuum, rather than a finite catalog of activities. The civic engagement continuum ranges from individual to collection action, single events to ongoing civic activities, charitable or goodwill activities, such as helping organizations and neighbors, to more socially-conscious efforts, such as advocacy and community organizing that address institutional and structural inequalities.

Current studies of civic and political participation in the United States typically measure traditional forms of engagement, such as voting, political campaigning or contributing to political campaigns. These studies typically find higher civic engagement by non-immigrant and middleclass populations. Therefore, the focus on traditional measures gives the impression that Latinos and Latinas are apathetic to participate civically and politically (Stoll \& Wong, 2007). In recent years, a surge of interest in studying nontraditional forms of engagement, in which noncitizens and nontraditional voters regularly participate, such as faith-based and social service volunteering, parent engagement in public schools, and transnational civic engagement has fueled the field. Researchers underline that participation in nontraditional activities or civic events strongly predict civic involvement of Latinos and Latinas (Ebert \& Okomato, 2013; Martinez, 2005). Therefore, engagement in community activities or school events can be predictors for future civic engagement. Responding to previous research described here, the National Latino Research Center created a suite of classes to help Latino community members of any educational background gain experience in both traditional and non-traditional forms of civic engagement.

\section{Theoretical Foundation}

The NLRC bases its work upon Tara Yosso's (2006) theory of cultural wealth, a strength-based framework that highlights the importance of beliefs and practices originating from the family and culture. Yosso developed the cultural wealth theory as a response to the deficit model 
perspective, often practiced in social service institutions, that views low-income people of color as having insufficient cultural capital to succeed. Deficit model thinking attributes negative social conditions to a person's cultural background; for example, the belief in the Sleeping Giant, defined as a lack of Latino political engagement despite growing population.

The NLRC specifically utilizes Yosso's six types of cultural wealth capital to understand the strengths that Latino families and communities already possess: (a) aspirational (hopes and dreams); (b) linguistic (power of storytelling); (c) familial (working as a collective); (d) social (working with neighbors); (e) navigational (street smarts and survival skills); and (f) resistance (encountering and dealing with oppressive conditions). Therefore, the NLRC conceptualizes members of the Latino community as having incredible assets to participate in civic engagement. Its curriculum operationalizes Yosso's cultural wealth theory, and this research study reflects a strength-based approach. Figure 1 shows Yosso's (2006) cultural wealth model.

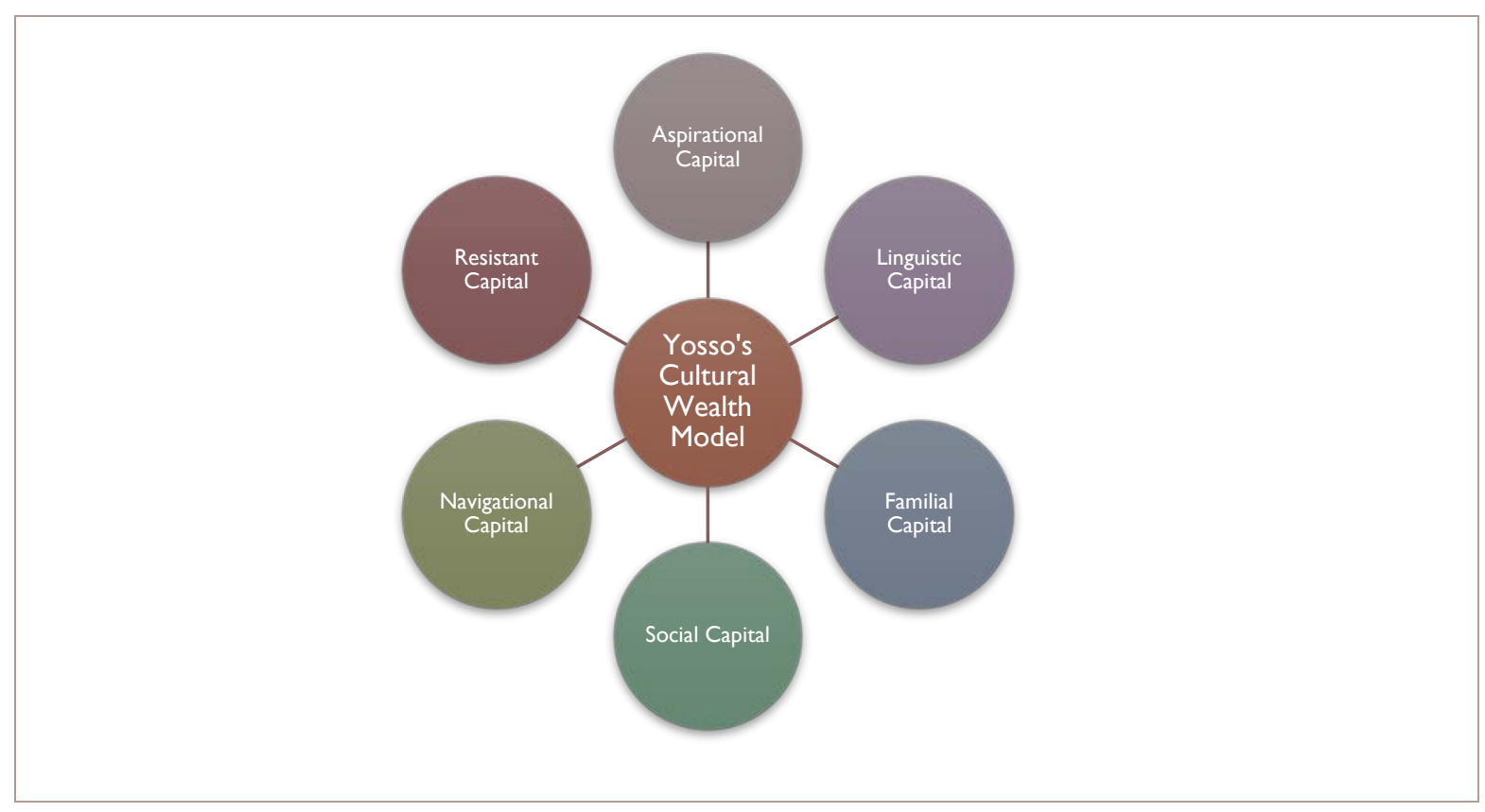

Figure 1. Cultural Wealth Model

\section{Universidad Popular-The People's University}

For the last ten years, the NLRC has coordinated a free community class called Universidad Popular. It is a unique and successful model of community education that originates from years of working side-by-side with community members and local leaders. Universidad Popular uses popular education pedagogy; it presents the material through a culturally appropriate and responsive lens in English, Spanish and bilingual formats, which resonate with participants' histories and lived experiences. Popular education is a pedagogical model based on Paulo Freire's (1970) approach of dialectic interchange and kinesthetic learning. An essential element to the model is of empowerment and connecting students' learning with their role in creating positive social change. 
A hallmark of Universidad Popular is that entire families attend and share learning together. The program recognizes the importance of the extended family and the need for a comprehensive approach to education and political integration (Wilkin et al., 2009). Research shows that students who learn in a family setting do better in school and develop stronger civic values (Kahne \& Sporte, 2008). There is no requirement of formal education attainment or grade level for adults or youth to participate in any of the Universidad Popular classes.

The collaborative nature of the Universidad Popular model has led to exciting developments across a broad range of topics that further enhance the lives of hundreds of community members.

First, Junior UP emerged when the children of those who were taking traditional Universidad Popular clamored for their own classes. Junior $U P$ students learn in a blend of English and Spanish with a focus on youth empowerment.

Second, Homie UP began when parents who were taking Universidad Popular courses expressed the desire for their sons and daughters (who were incarcerated) to experience such rigorous,

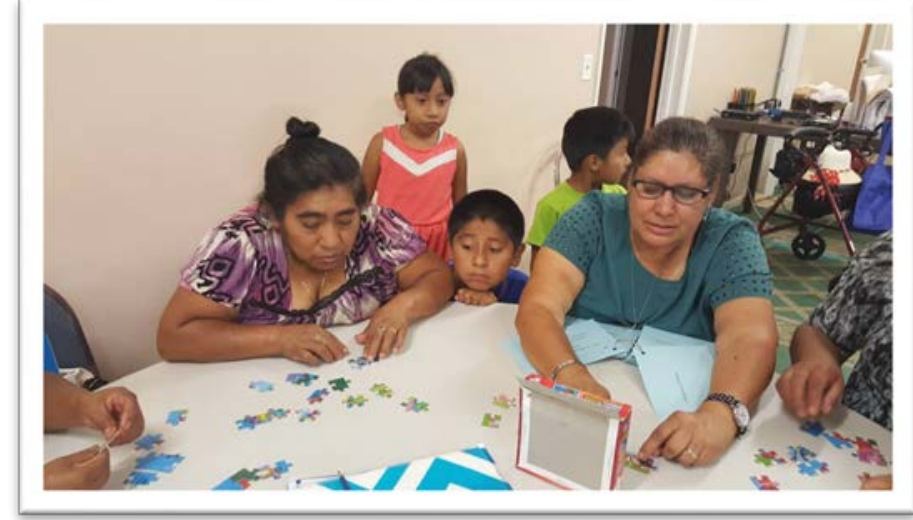

Families learn together in Universidad Popular exciting and comprehensive material. For the last eight years, Homie UP has offered a correspondence course with curriculum based on popular education pedagogy. Over three hundred incarcerated students take part, most of whom are serving long terms or life sentences. Homie UP has students in every state prison in CA and 13 federal prisons.

Third, after learning of family struggles around loved ones after their release from prison, Dr. Nuñez-Alvarez developed a course called Cultivando Liberación (Cultivating Liberation), which focuses on successful re-entry. A residential drug facility offers the course for those on parole. This curriculum focuses on reintegration and includes hands-on activities in community gardens, along with a focus on health and wellness.

Additionally, Universidad Popular has added more programs. Cultivando Salud (Cultivating Health) strengthens family and community to understand and reclaim indigenous notions of food, health and culture. Cultivando Sabiduría (Cultivating Wisdom) focuses on elders: their health, wellbeing, civic engagement and social needs. Cultivando Dignidad (Cultivating Dignity) offers a human-rights curriculum that serves immigrant community needs. Finally, Cultivando Liderazgo (Cultivating Leadership) brings to life the principles of democracy and the role of civil society in shaping government and policies to create change. Taken all together, the various Universidad Popular classes have included members of the Latino communities in the San Diego North County who have diverse needs, experiences, and interests. 


\section{The Cultivando Liderazgo Intervention}

The NLRC designed an intervention to increase Latino civic engagement. The eight-week Cultivando Liderazgo course drew upon known best practices for organizing a civic education curriculum (Bahmueller \& Quigley, 1991). The NLRC delivered the intervention by providing linguistically and culturally relevant civic engagement curriculum and presenting it in a collaborative, highly participatory pedagogical style. Cultivando Liderazgo builds upon community strengths, consisting of the knowledge and lived experience of individuals and families. The Corporation of National and Community Service funds this research.

Cultivando Liderazgo involves Latino youth, parents, and elders and works with individuals, families, and extended families. Additionally, participants often bring along to classes their neighbors and friends from other cities. The Cultivando Liderazgo intervention builds upon an eight-week curriculum founded on the principles of popular education. The program teaches civic engagement through a civil and human rights framework utilizing culturally appropriate materials to present content in a bilingual (English and Spanish) and multicultural format. Figure 2 shows Cultivando Liderazgo's conceptual model.

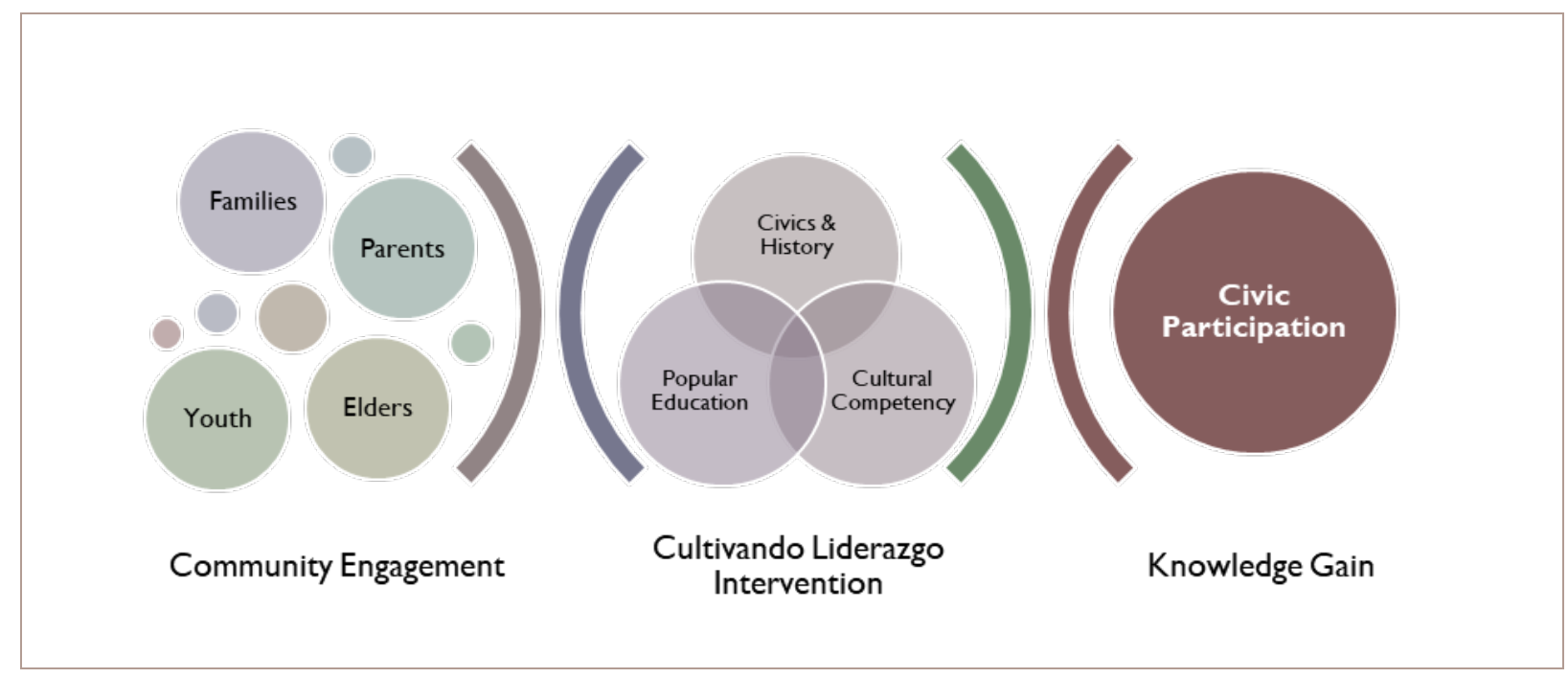

Figure 2. Conceptual Model for Cultivando Liderazgo

Cultivando Liderazgo participants differ in age, educational levels, language abilities, and professions. One of the target outcomes is for participants to improve their attitudes about civic engagement and increase participation in nontraditional and/or traditional forms of engagement.

A coalition of NLRC staff, CSUSM students, community volunteers and CSUSM professors organize the course and deliver the pedagogy. All educators receive intensive training from the NRLC leadership team on popular education pedagogy, ethics, and cultural sensitivity. The logistics are coordinated at the university offices of the NLRC but the courses hold their classes in community centers, library-meeting rooms, and other donated spaces throughout North County of San Diego. 
An essential element to the Universidad Popular model is of empowerment and connecting students' learning with their role in creating positive social change. Additionally, helping Latino students gain cultural and social capital is an explicit part of the curriculum (Segura et al., 2001). Table 1 shows features of the curriculum.

Table 1. Features of Cultivando Liderazgo Curriculum

Education is free and open to communities in San Diego County.

Classes meet weekly for two-hour periods at convenient times and locations.

Formal education is not a requirement for participation.

Students participate in traditional forms of civic engagement, serving as poll workers during election seasons, and doing voter registration.

Students participate in nontraditional forms of engagement, becoming peer-educators after completing the course.

Cultivando Liderazgo brings to life the principles of democracy and the role of civil society in shaping government and policies to create change. The core elements of the curriculum derive from the U.S. citizenship exam that focuses on civics education and U.S. history. Cultivando Liderazgo curriculum: (a) connects students' lives to government structures; (b) enacts democratic processes to enhance political knowledge and interest; (c) teaches about civil and human rights and exercising civic roles and responsibilities; and (d) introduces students to the functioning of local government via meetings with local representatives and visits to local civic and community forums.

Eight lessons in Cultivando Liderazgo curriculum are summarized in Figure 3, below.

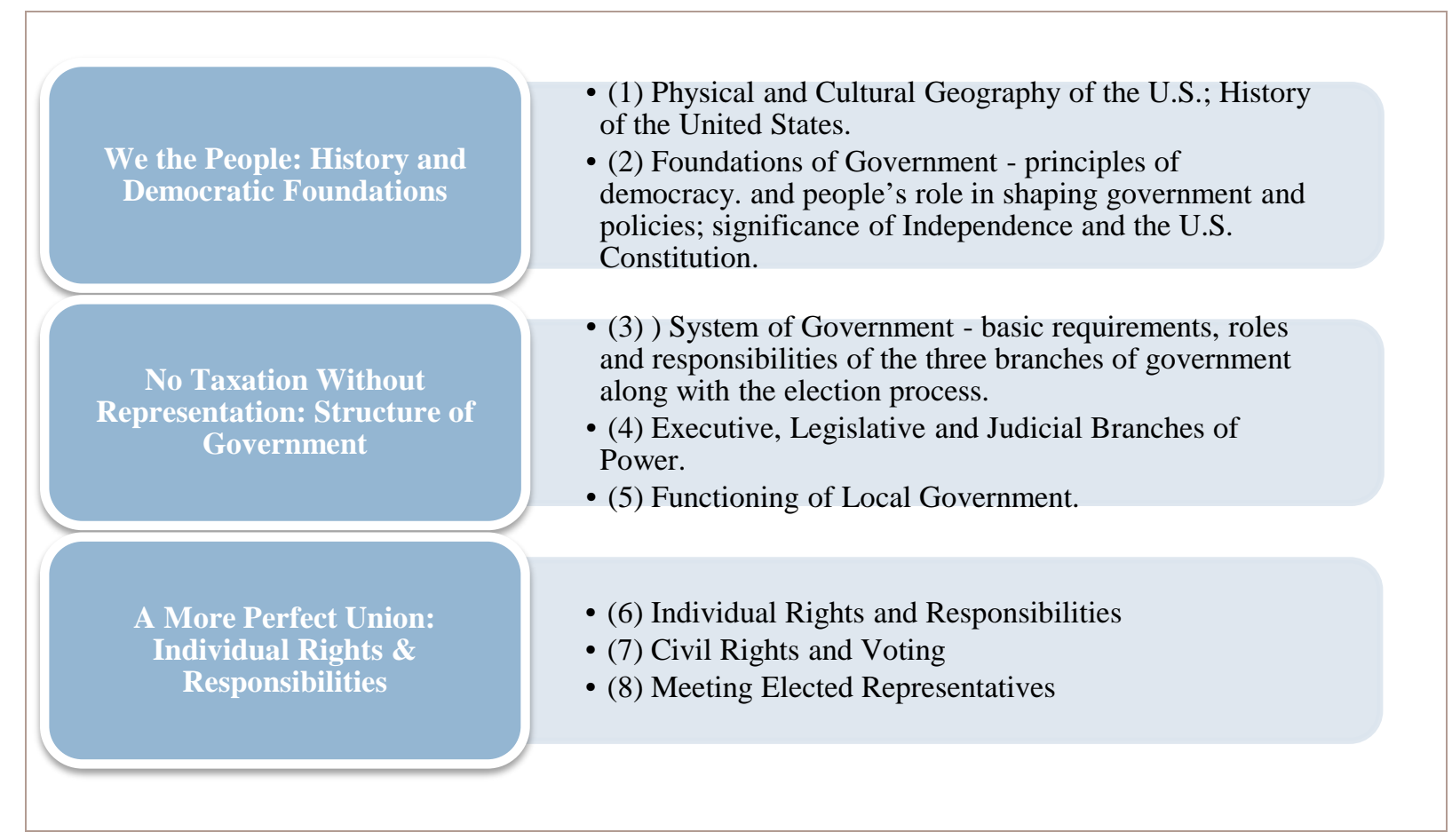

Figure 3. Universidad Popular’s Cultivando Liderazgo 


\section{Research Methodology}

Two hundred and fifteen participants completed the baseline survey at time of enrollment (T1), and all completed the follow-up survey at the end of the eight-week course (T2), with a 100\% response rate. This paper represents data on the initial analysis of a representative sample of participants, to display the preliminary effects of Cultivando Liderazgo (the community engagement model and intervention). The research project is in its third year and has concluded the last stage of data collection (T3, which is 3 months after T2).

\section{Data Collection}

The study examines the effects of Cultivando Liderazgo on levels of civic engagement of individual youth and adults. It used a mixed-methodology approach (quantitative and qualitative). At the individual level, the project examined effects of the curriculum on reported levels of engagement and types of engagement. Among adults (parents and grandparents), researchers tested effects on reported levels of engagement and types of engagement happening within the family. The focus was on the collection of process data, consistent with civic engagement standards, to determine whether the curriculum reached beyond the classroom, achieved desired effects, is potentially adoptable in other communities, was implemented with

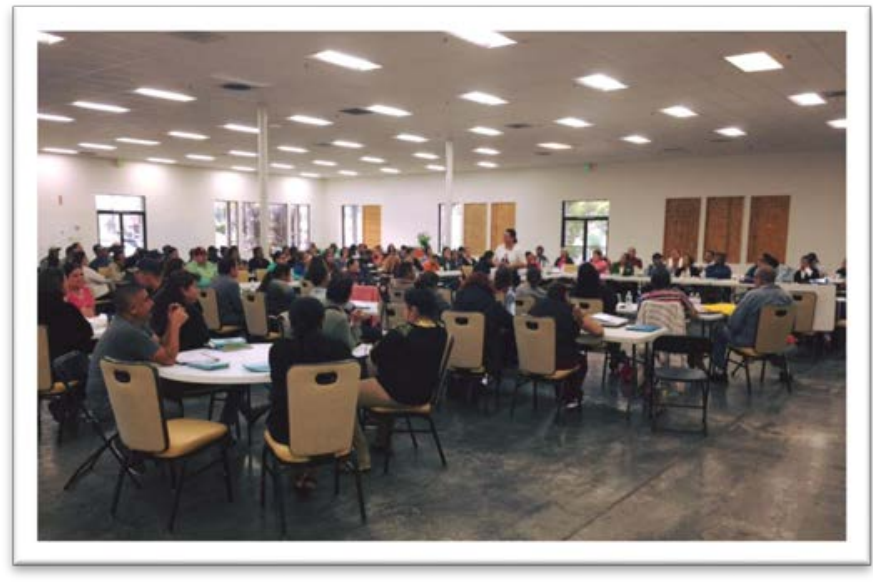

Cultivando Liderazgo Class in Vista, California fidelity, and whether effects can be maintained over three months.

Procedure. Trained bilingual and bicultural research assistants followed strict research protocols in implementing participant assessments, which consist of completing participant consents and conducting structured questionnaires in an interview format. Each participant received a twentydollar incentive for completing each assessment interview. Assessment interviews followed, via the phone, online, or in person at a time and location convenient for the participant.

The study was comprised of eleven cohorts. Cohorts were in different locations throughout the county to make participation accessible to residents in suburban (Vista, San Marcos, Escondido) rural areas (Valley Center/Ramona, Fallbrook) and remote rural areas (Pauma/Pala). These locations are feeder communities to the university. This report summarizes findings from six out of eleven Cultivando Liderazgo cohorts. We will analyze the remainder in the near future.

Assessment Protocols. All participants completed a comprehensive assessment questionnaire conducted as a structured interview that includes questions about demographic characteristics (including socio-economic indicators and family history), knowledge and attitudes toward civic engagement, volunteerism, civic and political participation activities, and a civics quiz. We 
administered the assessment tools in English and Spanish, depending on the language preference. The majority of the questions came from the United States Census Supplemental Surveys on Civic Engagement, Voting and Registration, Volunteers, Computer and Internet Use.

The civic knowledge and attitudes section provided a profile of participants' perceptions of civic engagement including personal beliefs toward civic engagement, opinions of elected officials and government, government concern for people, government accountability, and trust in government.

The civic participation section includes indicators from a national sample to reflect civic actions compared to national trends. It measured civic values, motives, and behaviors. Civic indicators include questions about community problem solving, volunteering group membership, and participation in charitable cause; electoral indicators include voter registration, voting, and involvement in political campaigns; indicators of political voice including contact with public officials, contact with news, and participation in protests, signing petitions, and canvassing.

We created subsections in the survey to measure youth, parents, and immigrants. We also had qualitative open-ended questions in the surveys to allow participants to describe other local civic events that emerge and that are unique to their regional location. Figure 4 shows the structure and timeline of the assessment.

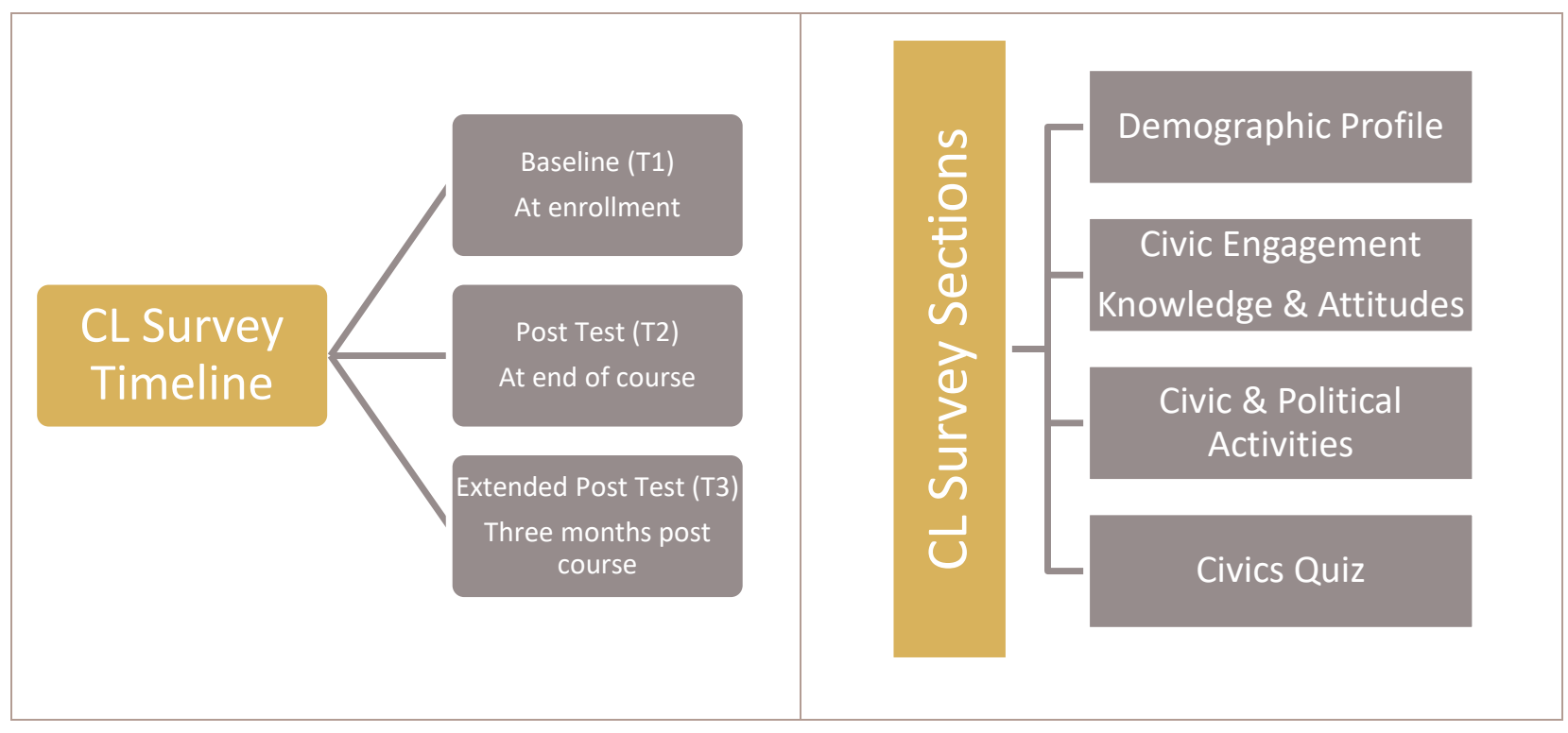

Figure 4. Timeline and Structure of CL Survey

\section{Quantitative Analysis}

Quantitative data were entered in a standard statistical program (Statistical Package for the Social Sciences: Version 23) and analyzed using standard statistical procedures. The totals for specific assessment items may not equal the overall sample size if some respondents left that 
item blank. Each data analysis and display presents the number of participants that responded to each item (e.g., sample size). Descriptive analysis (i.e., response frequencies) of each item also appears where appropriate.

Researchers applied various statistical tests based on the specific research question under scrutiny. Findings noted as "statistically significant" are based on a p-value less than or equal to 0.05, and indicate that compared groups were different from one another in a statistical sense, and the difference is unlikely by chance alone; significant findings are noted with an asterisk $\left(^{*}\right)$.

Though many participants completed the baseline (T1) and mid-point (T2) assessments, it is important to note that tests of significance are sensitive to sample size, such that the larger the sample size, the easier it is to show a statistically significant difference between two factors. When a significant difference between factors is found, other metrics should be explored to better understand the nature of the difference including the mean or median, standard deviation, and effect size (when calculated).

The authors calculated effect sizes to explore further the impact of the program on participant knowledge. The effect size is the magnitude, or size, of an effect. It is useful to include as it provides a "practical" or "meaningful" context to the difference between factors indicated by statistical significance (i.e., something can be statistically significant, but not meaningfully different). The range for effect sizes is typically from 0 to 1 . Specifically, for this project $r=0.2$ is considered a 'small' effect size, 0.5 represents a 'medium' effect size and 0.8 or greater is a 'large' effect size.

\section{Civic Knowledge Gains}

Participant Knowledge at Baseline and Post-Test Assessment. One of the ways that this study tested the efficacy of the Cultivando Liderazgo curriculum is by directly testing the participants' civic knowledge by administering a civic quiz at four intervals: (a) before the intervention (T1); (b) immediately at the end of the intervention (T2); and (c) three months after the course ended (T3). The following section describes the results of the civic quiz at the baseline and post-test assessment; the third assessment has yet to undergo analysis.

Each participant completed a 25-question civics quiz at baseline, at the end of the course, and three months after taking the course. Table 12 shows the statistical significance of each question in the civic quiz at baseline (T1) and post-test (T2).

Overall, results show significant improvement and knowledge gains for all participants. Overall quiz performance reveals a 10 percent gain in civics knowledge: 76 at baseline to 85 percent after the completion of the class. In every single measure of the civic quiz, there was improvement.

Civic Knowledge Gains by Cohort, Language, and Technology. The Cultivando Liderazgo classes took place in a variety of locations: suburban, rural and remote. One of our goals was to understand the role of place or geography on Latino civic engagement. For the purposes of this 
report, we analyzed the results of the civic quiz on a variety of factors, such as region, language, and access to technology.

Fidelity to the Cultivando Liderazgo intervention maintained at high levels at each implementation site. Meaning, the cohort leaders or instructors did not have individual class impact. Therefore, differences in cohort may result from internal characteristics (e.g., access to technology, age, gender) of the cohorts themselves. While all cohorts made significant improvements in their civic knowledge, the place of residence influenced knowledge gains. The Pauma/Pala cohorts, located in a remote area of the region, had significantly less knowledge at baseline (61.8) than other cohorts but made the largest gains (12.6+). The San Marcos cohort demonstrated a near ceiling effect. They already test high at baseline assessment (83.2) and so did not have room to make large gains (9.1+). One explanation is that the San Marcos site's participants were mainly educated youth. Vista had a baseline of 75 and increased their civic knowledge by 7.6 percent. Escondido, a suburban site, had a baseline of 72.8 and an increase of 8.9 percent. Future analysis will analyze additional factors contributing to the differences by region/cohort.

Language. We believed language mediates civic knowledge gains. Therefore, we created a composite score for English and Spanish language fluency and use. The higher the score the more the participant uses each language. These new language scores were analyzed using bivariate correlations. Table 2 shows that results revealed that language is significantly related to gains on the civic test.

Table 1. Effects of Language Spoken in Knowledge Gain

$r=-.16$

$p<.05$
The more Spanish spoken the lower civic knowledge at T2, but not at baseline (T1). $r=.40$

$p<.0001$
The more English spoken the higher the civic knowledge score at $\mathrm{T} 1$ and $\mathrm{T} 2$.

Technology. 'Having technology' we defined as having a smartphone, tablet, or computer with access to the interest. Cohort differences may link to technology. Having technology and access to technology, such as access to a library with computers that have free access to the internet or having access to public Wi-Fi mediate the civic knowledge gains. Table 3 indicates that technology and access to technology correlate significantly to gains on the civic test.

Table 2. Effects of Access and Use of Technology on Knowledge Gain

$r=-.34$

$p<.0001$

The more technology the participant possesses the higher their civic knowledge at T1 and T2. $r=.43$

$p<.0001$
The more access to technology the participant has, the higher their civic knowledge at T1 and $\mathrm{T} 2$.

Action \& Knowledge: Measuring Diverse forms of Civic Engagement. We also tested to see if various forms of political and civic engagement (as recorded at the baseline data-collection 
stage) affected their civic knowledge. This research project uniquely captured changes in patterns of traditional political involvement (e.g., voting, volunteering for candidates or political organizations, contributions to campaigns) and in nontraditional civic engagement activities (e.g., grassroots efforts aimed to shape local initiatives or produce positive social change at the community level) among Latino adults, elders, and youth.

While voting is a crucial aspect to civic engagement, this study captures diverse civic behaviors of Latinos during presidential elections in 2016 and measures of community grassroots organizing, social justice activity, volunteering, and other forms of civic engagement. Table 11 displays the civic engagement measures that we created to understand correlation to civic knowledge. To further explore the underlying factors associated with traditional and nontraditional civic engagement behaviors, several questions from the assessment were combined to create a subscale of seven domains to test for statistical significant to each factor examined; this is important to create more stable estimates and reduce experiment-wise type I error. A Type 1 error represents the probability of rejecting a finding when in fact it is true, also known as alpha $\alpha$. The scores from each domain as calculated as the average of all behavioral indicators described in Table 4.

Table 3. Measures of Traditional and Nontraditional Civic Involvement

\begin{tabular}{|c|c|}
\hline Score & Indicators \\
\hline $\begin{array}{l}\text { Total Engagement Score was computed } \\
\text { for all participants who reported on } \\
\text { traditional forms of volunteerism. }\end{array}$ & $\begin{array}{l}\text { Signing petitions, volunteering for a political } \\
\text { organization or political candidate, participated in } \\
\text { a protest, march, or demonstration, etc. }\end{array}$ \\
\hline $\begin{array}{l}\text { Parent Volunteerism Score was } \\
\text { computed for participants who identify as } \\
\text { parents. }\end{array}$ & $\begin{array}{l}\text { Volunteering at child's school, for child's } \\
\text { classroom, attending school events, etc. }\end{array}$ \\
\hline $\begin{array}{l}\text { Volunteerism Barriers Score was } \\
\text { computed for participants who reported } \\
\text { barriers to political engagement. }\end{array}$ & $\begin{array}{l}\text { Needing childcare, needing someone to take care } \\
\text { of my home responsibilities, lack of } \\
\text { transportation, limited English, etc. }\end{array}$ \\
\hline $\begin{array}{l}\text { Voter Engagement Score was computed } \\
\text { for participants who are eligible to vote. }\end{array}$ & $\begin{array}{l}\text { Registered to vote, voting in national/local } \\
\text { elections, planning to vote, etc. }\end{array}$ \\
\hline $\begin{array}{l}\text { Transnational Connections Score was } \\
\text { computed for participants who identify as } \\
\text { immigrants to the United States }\end{array}$ & $\begin{array}{l}\text { Owning property in their country of origin, } \\
\text { sending money to country of origin, having } \\
\text { knowledge of country of origin's politics, etc. }\end{array}$ \\
\hline $\begin{array}{l}\text { Transnational Civics Score was } \\
\text { computed for participants who identify as } \\
\text { immigrants to the United States and }\end{array}$ & $\begin{array}{l}\text { Reading/listening to news about issues regarding } \\
\text { country of origin, attending rally in U.S. about } \\
\text { country of origin issues, contributing to } \\
\text { campaigns for country of origin, etc. }\end{array}$ \\
\hline $\begin{array}{l}\text { Social Media Political Engagement } \\
\text { Score was computed for participants who } \\
\text { reported using social media. }\end{array}$ & $\begin{array}{l}\text { Following elected officials, political candidates, } \\
\text { and public figures in social media platforms (e.g., } \\
\text { Facebook, Twitter, Instagram, etc.) }\end{array}$ \\
\hline
\end{tabular}

These seven forms of political involvement were computed for each participant and were analyzed using a bivariate correlation. Based on the initial assessment (baseline), the gains in civic knowledge are correlated to total engagement scores, voter patterns, and social media 
political engagement scores. Figure 5 shows the scoring cluster with significant correlations. We will analyze these effects further once T3 is collected.

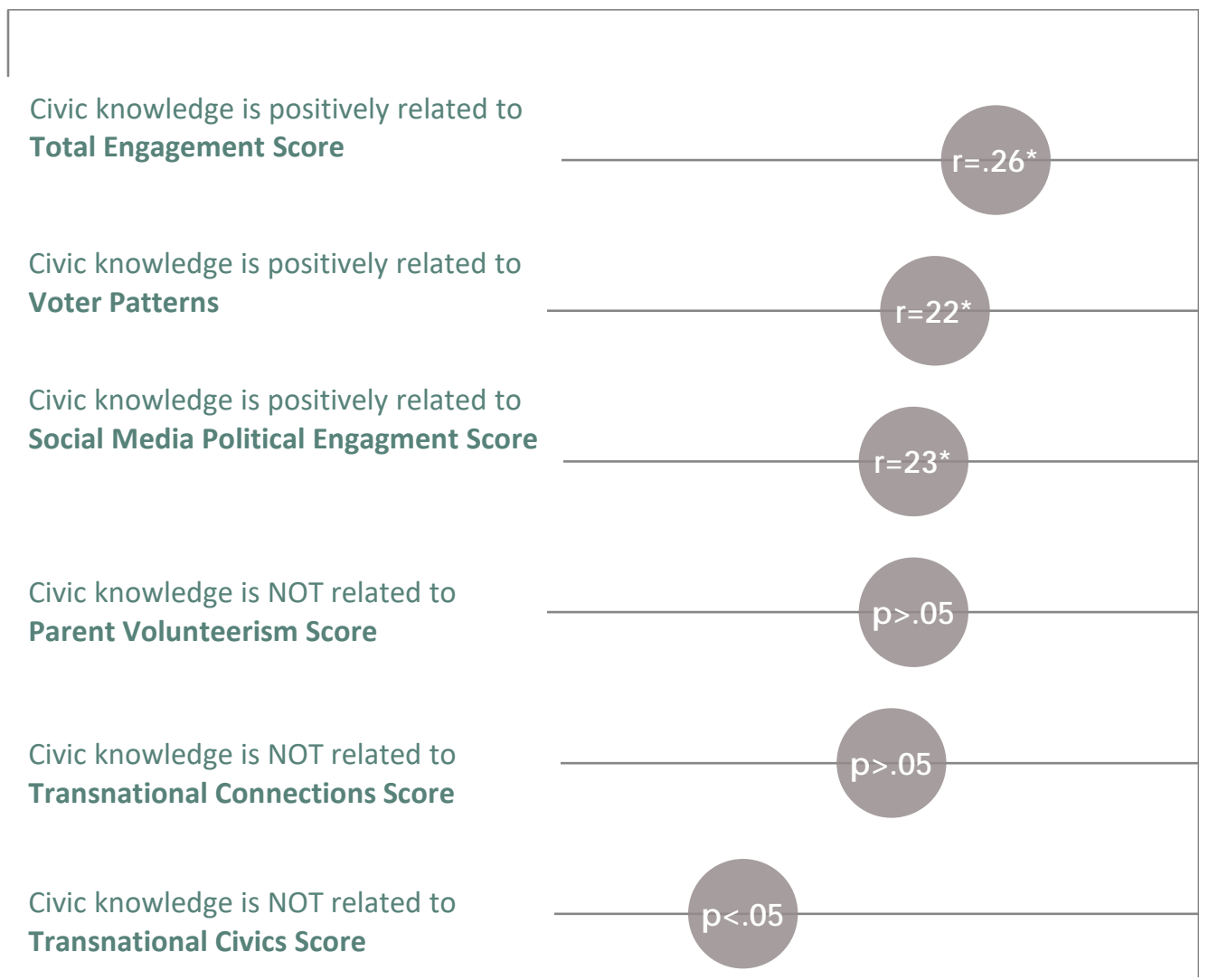

Figure 5. Correlations of Civic Engagement on Civic Knowledge

\section{Discussion}

The findings on the impact of Cultivando Liderazgo are promising. First, the students showed significant improvement on their civic knowledge through engaging in hands-on activities. The curriculum derives from on a popular education model that values lived experience and "learning by doing," and focuses on learning for social justice. Participating directly in democracy, such as signing petitions, volunteering, protesting, and voting the students' s made a powerful and significant impact on the participants' civic knowledge.

While the authors measured traditional media, such as watching the television news (in Spanish and English) and reading the newspaper, the participants' social media engagement about politics significantly and positively correlated with their civic knowledge. Social media also represents a tangible and relatively cost-free way to engage community members in civic engagement. Social media participation is a newer form of civic engagement (Smith, 2013), so our findings are likely to make a strong contribution to the field. These preliminary findings do 
not support the "clickivism" or "slackivism" thesis that argues online political engagement is fleeting and does not translate into offline political participation, such as voting (Howard et al., 2016). Rather, our research supports De Zuñiga and colleagues' (2012) study that seeking information and news online supports offline political participation and civic engagement. They found social media fosters the democratic process and increases participants' social capital.

Researchers have also written about the ways that social media (e.g., YouTube, Twitter, Facebook) have allowed marginalized groups to embark on powerful social justice campaigns (Atony \& Thomas, 2010; Byrne, 2013; Valenzuela, 2013). There is an exciting opportunity for our study to extend the understanding of Latinos, social media and civic engagement. For example, Latinos have the highest rate of Facebook usage, compared to whites and blacks, and use YouTube for news more so than whites (Krogstgad, 2015). We look forward to exploring the data with additional statistical testing.

\section{Conclusion}

This research study is the first of its kind conducted with Latino communities in San Diego County. Although local efforts to engage Latino communities in this region are not new, the implementation and study of a culturally and linguistically relevant civics curriculum grounded on popular education pedagogy is a novel initiative. Cultivando Liderazgo intentionally cultivates the participation of vulnerable and hard-to-reach communities. Cultivando Liderazgo has had a far scope in San Diego County. Hundreds of community residents, elders, youth, families, and students have participated in the project, as research participants or research assistants. Above all, study findings show promising results for the importance of using a respectful, strength-based and human rights framework and begin to illuminate the efficacy of the approach 


\section{References}

Abrajano, M.A. \& Alvarez, R.M. 2010. Assessing the causes and effects of political trust among U.S. Latinos. American Politics Research, 38(1),110-141.

https://doi.org/10.1177/1532673X08330273

Antony, M.G \& Thomas, R.J. (2010). 'This is citizen journalism at its finest': YouTube and the public sphere in the Oscar Grant shooting incident. New Media and Society, 12(8), 1280-1296. https://doi.org/10.1177/1461444810362492

Bahmueller, C.F. \& Quigley, C.N. (Editors). (1991). CIVITAS: A Framework for Civic Education. Calabasas, CA: Center for Civic Education. Retrieved from http://www.civiced.org/resources/publications/resource-materials/civitas-a-framework-for-civiceducation

Byrne, D.N. (2013). 419 Digilantes and the frontier of radical justice online. Radical History Review, 117: 70-82. https://doi.org/10.1215/01636545-2210464

De Zúñiga, H.G., Jung, N. \& Valenzuela, S. (2012). Social Media Use for News and Individuals' Social Capital, Civic Engagement and Political Participation. Journal of Computer-Mediated Communication, 17(3), 319-336. https://doi.org/10.1111/j.1083-6101.2012.01574.X

Ebert, K. \& Okamoto, D.G. (2013). Social citizenship, integration and collective action: Immigrant civic engagement in the U.S. Social Forces, 91(4), 12671292. https://doi.org/10.1093/sf/sot009

Freire, P. 1970. Pedagogy of the Oppressed. New York: Bloomsbury Academic.

Garcia Bedolla, L. (2012). Latino education, civic engagement, and the public good. Review of Research in Education, 36(1):23. https://doi.org/10.3102/0091732X11422666

Howard, P.N., Savage, S., Saviaga, C.F., Toxtli, C. \& Monroy-Hernández, A. (2016). Social media, civic engagement and slacktivism hypothesis: Lessons from 'El Bronco'. Journal of International Affairs, 70(1):55-73.

Krogstgad, J.M. (2015, February 3). Social media preferences by race and ethnicity. Pew Research Center: FactTank News in the Numbers. Retrieved from http://www.pewresearch.org/fact-tank/2015/02/03/social-media-preferences-vary-by-race-andethnicity/)

Martinez, L.M. (2005). Yes we can. Social Forces, 84(1), 135-155. https://doi.org/10.1353/sof.2005.0113

Peterson, T. (2014). Reviving and revising the civic mission: A radical re-imagining of "civic engagement." Metropolitan Universities, 25(3), 17-30. Retrieved from https://journals.iupui.edu/index.php/muj/article/view/20579/20179 
Segura, G., Pachon, H. \& Nathan, D.W. (2001). Hispanics, social capital, and civic engagement. National Civic Review, 90(1), 85-96. https://doi.org/10.1002/ncr.90108

Smith, A. (2013, April 25). Report: Civic engagement in the digital age. PEW Research Center on Internet and Technology. Retrieved from http://www.pewinternet.org/2013/04/25/civicengagement-in-the-digital-age/.

Stoll, M.A. \& Wong, J.S. (2007). Immigration and civic participation in a multiracial and multiethnic context. International Migration Review, 41(4):880-908.

https://doi.org/10.1111/j.1747-7379.2007.00104.x

Valenzuela, S. (2013). Unpacking the use of social media for protest behavior: The roles of information, opinion on expression, and activism. American Behavioral Scientist, 57(7), 920942. https://doi.org/10.1177/0002764213479375

Wilkin, H.A., Katz, V.S, \& Ball-Rokeach, S.J. (2009). The Role of interaction in new immigrant Latinos’ civic engagement. Journal of Communication, 59(2), 387-406.

https://doi.org/10.1111/j.1460-2466.2009.01421.x

Yep, K. (2014). Reimagining diversity work: Multigenerational learning, adult immigrants, and dialogical community-based learning. Metropolitan Universities, 25(3):47-66. Retrieved from https://journals.iupui.edu/index.php/muj/article/view/20581

Yosso, T. J. (2005). Whose culture has capital? A critical race theory discussion of community cultural wealth. Race Ethnicity and Education, 8(1), 69-91.

https://doi.org/10.1080/1361332052000341006 


\section{Author Information}

Arcela Nuñez-Alvarez is Research Director of the National Latino Research Center at California State University San Marcos where she works on community-based participatory action research projects focused on civic literacy, education, incarceration and environmental justice.

* Arcela Nunez-Alvarez, Ph.D.

National Latino Research Center

California State University San Marcos

333 S. Twin Oaks Valley Road

San Marcos, CA 92096

Telephone: 760-750-3503

Email: anunez@csusm.edu

Marisol Clark-Ibáñez is a full professor in the Sociology Department at California State University San Marcos. She is the Faculty Director of the National Latino Research Center where she works on applied research projects in the community, on such topics as civic engagement, education, immigration, and incarceration.

Marisol Clark-Ibáñez, Ph.D.

California State University San Marcos

333 S. Twin Oaks Valley Road

San Marcos, CA 92096

Telephone: 760-750-4631

Email: mibanez@csusm.edu

Ana M. Ardón is an applied sociologist examining and addressing historical, racial, political and socio-economic disparities in Latino communities through the lens of intersectionality, critical race theory, and applied action research. She is a Researcher at the National Latino Research Center at California State University San Marcos focused on youth empowerment, education, and civic and political education.

Ana M. Ardón, M.A.

National Latino Research Center

California State University San Marcos

333 S. Twin Oaks Valley Road

San Marcos, CA 92096

Telephone: 760-750-3505

Email: aardon@csusm.edu 
Amy L. Ramos is professor of Psychology in the Department of Behavioral Sciences at Grossmont Community College and Research Associate at Harder and Company Community Research. She evaluates Cultivando Liderazgo research for the National Latino Research Center.

Amy L. Ramos, Ph.D.

Department of Behavioral Sciences

Grossmont College

8800 Grossmont College Drive

El Cajon, California 92020

Telephone: 619-644-7562

Email: amy.ramos@gcccd.edu

Michelle Ramos Pellicia is an Associate Professor of Hispanic Sociolinguistic and Applied Linguistics in the Department of Modern Language Studies at California State University San Marcos. She is a Research Associate of the National Latino Research Center.

Michelle Ramos Pellicia, Ph.D.

Department of Modern Languages Studies

California State University San Marcos

333 S. Twin Oaks Valley Road

San Marcos, CA 92096

Telephone: 760-750-8006

Email:mramos@csusm.edu

* Corresponding author 